vol.1 No.1 ISSN:18235-2014

\title{
Training Nurses About Applying Disinfection Technique For Safe Reuse Of Disposable Suction Catheters For Neonates On Mechanical Ventilation. \\ By
}

\author{
${ }^{1}$ Rabab El-sayed Hassan El-sayed, ${ }^{2}$ Laila Younis Abu-Salem, \\ ${ }^{3}$ Heba Elsayed Abd Elmoniem Degla \\ 1,2 Pediatric Nursing, Faculty of Nursing, Mansoura University, \\ ${ }^{3}$ Medical Microbiology \& Immunology, Faculty of Medicine, Mansoura University, \\ E-mail of the corresponding author: biboelsayed9@yahoo.com
}

\begin{abstract}
Background: Endotracheal suctioning is designed to efficiently eliminating broncho-pulmonary secretions from the airway while avoiding the potential hazards of ventilator associated pneumonia (VAP). However, the cost of frequent tracheal suctioning for ventilated neonates admitted to the neonatal intensive care unit (NICU) has become a concern. One major cost component to provide this nursing care in a competent way is the use of a disposable suction catheter each time. The aim of the present study was to train nurses about applying disinfection technique for safe reuse of disposable suction catheters for neonates on mechanical ventilation, and to evaluate whether the repetitive use of disposable suction catheters is cost-effective over the single use. Methods: A quasi-experimental design was used. The disinfection technique was applied on 60 disposable endotracheal suction catheters used by a convenient sample of neonates $(n=30)$ who admitted to the NICU affiliated to El-Mansoura University Children's Hospital suffered from respiratory distress (RD) that required mechanical ventilation. An assessment sheet contained 2 checklists about the steps of suctioning the airway and catheter's disinfection was used. Results: The studied neonates admission weight was ranged from 905-3600 gm, gestational age was from 26-43 weeks; the period of intubation was between 2-26 days. The applied steps were found to be highly effective, completely (100\%) eliminating bacterial growth of catheters seeded with Staphylococcus Aureus, Klebsiella, Pseudomonas, and E-coli. Furthermore, it does not contaminate the catheters that are cultured negative for bacterial growth. Conclusion: Applying the study disinfection technique ensured safe reuse of disposable suction catheters for neonates on mechanical ventilation and reduced NICU's financial burden. Recommendation: For safe reuse and cost saving, suction catheters might be disinfected and reused. Further studies to find-out for how long could the nurse reuse the disposable suction catheter after disinfection is needed.
\end{abstract}

Key words: disinfection, NICU, disposable suction catheters, ventilator-associated pneumonia(VAP)

Introduction:

Endotracheal intubation inhibits the cough reflex and interferes with normal muco-cillary function, increasing airway secretion production and decreasing the ability to clear secretions. Therefore, endotracheal tube (ETT) suctioning is a frequently performed procedure for infants admitted to the NICUs on mechanical ventilation [1]. Techniques of suctioning are designed to efficiently clear the airway of mucus, while avoiding the potential hazards of infection [2]. Removal of such secretions also minimizes the risk of atelectasis. However, it is not a benign procedure and adverse physiological effects directly attributed to airway suction are well known [3]. It was stated that, endotracheal suctioning (ETS) is a procedure that may constitute a risk factor for ventilatorassociated pneumonia (VAP) by increasing microbial colonization of the lower airway [4].

Unsafe ETS practices have been observed worldwide during recent years. Because of adverse reactions, practitioners need to take all necessary precautions to ensure neonatal safety and a high quality of nursing care ${ }^{[5]}$. Airway suctioning may be performed as a "clean" procedure. However, disinfection is a modified aseptic technique, which eliminates a defined scope of pathogenic microorganisms but not necessarily all microbial forms. It reduces the number of micro-organisms to a level at which they are not harmful, avoids introducing the majority of micro-organisms to a susceptible site and prevents cross infection [6]. There is no clear evidence showing that this practice is absolutely wrong if applied on the disposable suction catheter so that it can be reused for the same patient. Disinfection differs from an aseptic 
technique, as the use of sterile equipment and the environment are not as crucial as would be required for asepsis ${ }^{[7]}$.

Clinical trials were discussed infection control practices while suctioning the ETT in healthcare facilities. One of them reported that, although disposable suction catheters are designed for single procedure use only, the same catheter might be reused only if an immediate further attempt at airway suction is required. Another trial suggested the duration of single use suction catheter before it is cleaned or replaced, recommended that, the catheter may be cleaned after each suctioning procedure, or changed every 8 to 24 hours unless catheter become contaminated (i.e. if dropped on the floor) [8]. However, catheters must be changed between suction of an artificial airway and mouth/nostrils to minimize cross-infection. The frequency of suctioning is determined by the infant's clinical condition, including chest auscultation, and not pre-determined time intervals ${ }^{[4]}$.

Therefore, the cost effectiveness of tracheal suctioning for ventilated neonates has become a concern. One major cost component of this care is related to the frequent use of disposable suction catheters [9]. The large number of suction catheters used may be coupled with limited resources. Therefore, reusable suction catheter is recommended in some hospitals then, it became a common practice to reduce treatment costs, even though it is designed to be disposable or of single use [10]. Hospitalization brings associated risks, including risk of infection.

Nosocomial infections or hospitalassociated infections have been identified as one of the most serious patient safety issues in health care [11]. The outcome of this nosocomial infection depends on several risk factors such as patient-related risk factors include severity of illness, immunesuppression, and length of hospital stay, as well as colonization of the respiratory tract with facultative pathogenic microorganisms [12]. VAP is the most common nosocomial infection among mechanically ventilated neonates. It doubles the risk of death, significantly increases NICU length of stay, and adds a huge financial burden to each affected patient's hospital costs ${ }^{[13]}$.

Recent guidelines related to procedures for cleaning, sterilizing or disinfecting and maintaining respiratory equipment now have a strong evidence base ${ }^{[14]}$. Many unresolved issues remain regarding optimal procedures for respiratory tract secretion suctioning, including whether sterile or clean gloves should be used when performing endotracheal suctioning and whether multiuse or single use suction catheters are more effective in prevention of VAP. The Centers for Disease Control and Prevention (CDC) reported that, although some of the interventions to reduce nosocomial pneumonia are the responsibility of physicians or other health care workers, many of the interventions are the direct responsibility of nurses or can be influenced by nurses ${ }^{[15]}$. The CDC urges education of nursing staff in implementing intervention efforts to prevent hospital-associated pneumonia. Education aimed at reducing the occurrence of risk factors and practice modifications demonstrated beneficial results ${ }^{[16]}$.

In pediatric population, the published data is placed great emphasis on standardization of practices related to care of respiratory equipment or resource utilization with respect to antibiotic administration. Furthermore, recommendations related to procedures for cleaning, sterilizing, or disinfecting, and maintaining respiratory equipment; including suction catheter now have a strong evidence base, and those recommended procedures are presented in detail in recent CDC reports [17 \& 18].

\section{Significance of the study:}

During mechanical ventilation, secretion accumulates in the artificial airway occluding the ETT and resulting in an increased respiratory workload. In addition, this is accompanied with the formation of microbial clusters inside the tube, which likely acts as a reservoir of pathogens 
Training Nurses About Applying Disinfection etc...

causing recurrent infections. The neonatal nurse should suction the ETT to clear secretions and to maintain airway patency, which optimize oxygenation and ventilation in a ventilated infant. Nevertheless, using a large number of disposable suction catheters throughout the period of hospital stay with limited resources in the developing countries including Egypt is a clinical challenge. Therefore, the current trial aims to ensure the best use of available resources through disinfection of disposable suction catheter after each session of suctioning. This helps prevent infection as well as cut down costs by reusing the same catheter for longer period.

Aims of study: The study aims were to:

1- Train nurses about applying disinfection technique for safe reuse of disposable suction catheters for neonates on mechanical ventilation.

2- Evaluate whether the repetitive use of disinfected disposable suction catheters is cost-effective over the single use for neonates on mechanical ventilation.

\section{Research hypothesis:}

1-Applying disinfection technique will ensure safe reuse of disposable suction catheters for neonates on mechanical ventilation.

2-Applying disinfection technique on disposable endotracheal suction catheters will reduce the NICU's financial burden.

3-Applying disinfection technique will minimize the NICU's waste disposals through repeated use of endotracheal suction catheters for ventilated neonates.

\section{Subjects and Method:- \\ Study Design:-}

A quasi-experimental design was used in this study.

\section{Setting:-}

The NICU affiliated to El-Mansoura University Children's Hospital. This unit is a tertiary care unit that provides free emergency care for the general population. Microbiological analysis was performed in the lab of Medical Microbiology \& Immunology Department, affiliated to
Faculty of Medicine, El-Mansoura University.

\section{Subjects:}

A convenient sample of 30 neonates was included in the study. The disinfection technique was applied on 60 disposable endotracheal suction catheters of different sizes (6 and $8 \mathrm{~F}$ ), which suctioned the airway of the study subjects. Neonates were entered into the study if they admitted in the study setting during the period of January $1^{\text {st }}$ until March 31 st, 2008, diagnosed as have grade three RDS, with artificial airway (ETT) and required mechanical ventilation for more than 24 hours. Sample size was calculated based on a confidence level of $95 \%$, power value of $80 \%$, degree of variability of $50 \%$ and sampling error of $10 \%$.

\section{Tools:}

1. An assessment sheet; contained:

a-Socio-demographic sheet which developed by the researcher to collect data about neonate's gestational age (GA), post-natal age (PNA), birth weight (BW), current weight, gender, and diagnosis.

b-Two checklists, the first one contained nine ideal major steps of suctioning the endotracheal tube, while the other contained the five main steps of applying the study disinfection technique, which was developed, and applied by the researcher to train the NICU nurses.

2. Microbiology laboratory report, which contained the result of catheter tip cultures, identifying catheter related infections using the semi-quantitative method described in 1977 by Maki et al. The report contained columns related to agar media, incubator temperature and microbial growth colonies (positive or negative microbial growth).

\section{Technique :}

- An official request to conduct the study was directed from the Dean of Faculty of Nursing, El-Mansoura University to the Head of the NICU. Tools are developed.

- The researchers met the authorized health care providers (physicians and nurses) in 
the study setting, explained the study aims, and methodology of data collection.

- As soon as the study idea agreement was obtained, each neonate was suctioned twice at the same time by catheter (A) and (B). The tips of both catheters were separated (using sterile scissor) and sent in sterile containers to the microbiology laboratory to be cultured for bacterial growth after a typical disinfection technique had applied on suction catheter (A), while catheter (B) sent without any intervention as a control.

- The disinfection technique applied on catheter (A) can be described in five main steps. (1) cleaning the disposable catheter by flushing with sterile hot, soapy water $10 \%$ concentration solution $(10 \mathrm{ml}$ of neutral detergent liquid dissolved in 1 liter of water, which is already used for cleaning suction vacuums) and then rinse with sterile water (tap water boiled for 5 minutes), (2) disinfecting the suction catheter by immersing it for 20 minutes in acetic acid of $5 \%$ concentration [19], (3) rinsing the catheter inside and outside by flushing sterile water, (4) dry by sweeping the catheters outer side using sterile gauze with ethyl alcohol 95\% concentration in one direction over 15 seconds, starting from the catheter tip toward the connection part ${ }^{[20]}$ and finally, (5) wrap the catheter in a clean dry towel.

- For cost effectiveness, the number of suction catheters routinely used for each neonate per 24 hours was counted, and the cost of substances that used in applying the study disinfection technique on disposable suction catheter was also calculated.

\section{Validity and reliability:}

- An Expert Panel composed of 3 pediatric medicine professors with their specialty in neonates, including the head of the NICU provided scientific oversight and direction for all aspects of the study content validity. On completion of the research plan, data collection took its place under Panel supervision and continuous evaluation of the outcomes.

\section{Pilot study :}

- A pilot study was carried out on six disposable suction catheters used to suction the ETT of three neonates $(10 \%$ of the study sample), which were excluded from the subjects. Accordingly, any modification was done to improve the study technique quality and efficiency.

\section{Ethical consideration:}

- Since suctioning is a harmless procedure that is routinely performed in the NICU, parental informed consents were not obtained.

\section{Data analysis :}

Data analysis and presentation were represented as descriptive results in the form of frequency and percentage and mean and standard deviation.

\section{Results:}

Table 1: shows the general characteristics of the study population. It is clear that male to female neonates' ratio was $1: 1$. One third of the study population aged 10 to less than 15 days postnatal, while $30 \%$ of them belonged to the age group of 5 to less than 10 days. The gestational age was 30 to less than 35 weeks in half of the subjects and $43.3 \%$ of neonates were intubated for less than 5 days. Their admission weight was 3000 gm or more in about one third of the sample. 
Training Nurses About Applying Disinfection etc...

\begin{tabular}{|c|c|c|}
\hline \multicolumn{3}{|c|}{$\begin{array}{l}\text { Table (1): General characteristics of the study } \\
\text { population }(n=30)\end{array}$} \\
\hline Characteristics & $\mathrm{n}=\mathbf{3 0}$ & $\%$ \\
\hline $\begin{aligned} \text { Gender: } & \\
\text { - } & \text { Male } \\
\text { - } & \text { Female }\end{aligned}$ & $\begin{array}{l}15 \\
15\end{array}$ & $\begin{array}{l}50 \\
50\end{array}$ \\
\hline $\begin{array}{ll}\text { Post natal age (days): } \\
\text { - } & \text { Less than } 5 \text { days } \\
\text { - } & 5- \\
\text { - } & 10- \\
\text { - } & 15- \\
\text { - } & 20 \& \text { more }\end{array}$ & $\begin{array}{c}2 \\
9 \\
10 \\
3 \\
6\end{array}$ & $\begin{array}{c}6.7 \\
30 \\
33.3 \\
10 \\
20\end{array}$ \\
\hline \multicolumn{3}{|c|}{$\mathrm{X}^{-} \pm \mathrm{SD}=12.3 \pm 6.3$} \\
\hline $\begin{array}{cl}\text { Gestational age (weeks): } \\
\text { - } & 25- \\
\text { - } & 30- \\
\text { - } & 35- \\
\text { - } & 40 \& \text { more }\end{array}$ & $\begin{array}{c}1 \\
15 \\
10 \\
4\end{array}$ & $\begin{array}{c}3.3 \\
50 \\
33 \\
13.3\end{array}$ \\
\hline \multicolumn{3}{|c|}{$\mathrm{X}^{-} \pm \mathrm{SD}=34.4 \pm 4.1$} \\
\hline $\begin{array}{ll}\text { Period of intubation (days): } \\
\text { - } & \text { Less than } 5 \text { days } \\
\text { - } & 5- \\
\text { - } & 10- \\
\text { - } & 15- \\
\text { - } & 20 \text { days \& more }\end{array}$ & $\begin{array}{l}13 \\
6 \\
5 \\
2 \\
4\end{array}$ & $\begin{array}{c}43.3 \\
20 \\
16.7 \\
6.7 \\
13.3\end{array}$ \\
\hline $\mathrm{X}^{-} \pm \mathrm{SD}=12.3 \pm 6.3$ & & \\
\hline $\begin{array}{cc}\text { Neonates' admission weight } \\
\text { (gm.) } \\
\text { - } & \text { less than } 1000 \\
\text { - } & 1000-<1500 \\
\text { - } & 1500-<2000 \\
\text { - } & 2000-<2500 \\
\text { - } \quad 2500-<3000 \\
\text { - } \quad 3000 \& \text { more }\end{array}$ & $\begin{array}{l}2 \\
8 \\
7 \\
0 \\
4 \\
9\end{array}$ & $\begin{array}{c}6.7 \\
26.7 \\
23.3 \\
0 \\
13.3 \\
30\end{array}$ \\
\hline $\mathrm{X}^{-} \pm \mathrm{SD}=2.128$ & & \\
\hline
\end{tabular}

Table 2: presents that, three fifths of the admitted neonates were diagnosed with respiratory distress syndrome. Respiratory failure, meconium aspiration syndrome, diaphragmatic hernia, infant of diabetic mother and hypoxic ischemic encephalopathy were found to be the diagnosis for the rest of the sample $(6.7 \%$ for each diagnosis).

Table (2): Distribution of mechanically ventilated neonates according to their diagnosis $(n=30)$

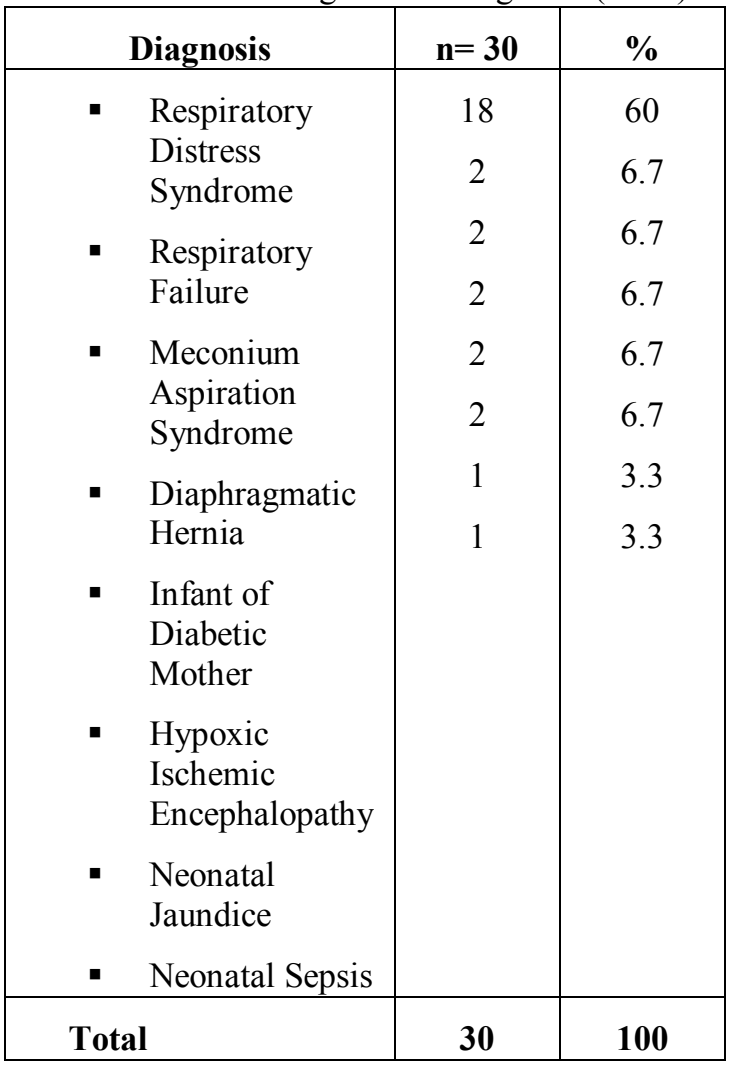

Table 3: shows the isolated organisms as identified by the microbiological profile of suction catheter's tips (A) and (B). Many types of organisms were detected by culture and sensitivity test of the disposable endotracheal suction catheters (B) or the controls; including Pseudomonas or Klebsiella (20\%), Staphylococcus (13.3\%), and E-Coli (10\%). On the other side, 100\% of catheters (A) became free from microbial colonization detected on catheters (B) surfaces in response to applying the study disinfection technique. Moreover, the study technique does not contaminate the catheters that are cultured as negative for bacterial growth 
Table (3): Distribution of organisms as isolated from disposable suction catheters with and without applying the study disinfection technique $\mathrm{A}$ and $\mathrm{B}$ respectively

\begin{tabular}{|ll|c|c|c|c|}
\hline \multirow{2}{*}{ Isolated Organisms } & \multicolumn{2}{c|}{ Catheters B } & \multicolumn{2}{c|}{ Catheters A } \\
\cline { 3 - 6 } & & No & $\mathbf{\%}$ & No & $\%$ \\
\hline Positive: & & & & \\
& - Pseudomonus & 6 & 20 & 0 & 0 \\
& - Klebsiella & 6 & 20 & 0 & 0 \\
& - Staphylococcus & 4 & 13.3 & 0 & 0 \\
- E-Coli & 3 & 10 & 0 & 0 \\
\hline Total & & 19 & 63.3 & 0 & 0 \\
\hline Negative & & 11 & 36.7 & 30 & 100 \\
\hline Total & & $\mathbf{3 0}$ & $\mathbf{1 0 0}$ & $\mathbf{3 0}$ & $\mathbf{1 0 0}$ \\
\hline
\end{tabular}

Table 4: It is clear from table (4) that, the mean number of disposable suction catheters used/day for each neonate was 8 catheters, which cost eight Egyptian Pounds (L.E), compared with only two Egyptian Pounds; one-pound cost of the catheter plus one L.E for the catheter's cleaning and disinfectant solutions to apply the study disinfection technique

Table (4): Mean number and cost of disposable suction catheters used/day for each neonate before and after application of the study disinfection technique

\begin{tabular}{|l|c|c|}
\hline Number \& Cost & $\begin{array}{c}\text { Before } \\
\text { applying } \\
\text { the study } \\
\text { technique }\end{array}$ & $\begin{array}{c}\text { After } \\
\text { applying } \\
\text { the study } \\
\text { technique }\end{array}$ \\
\hline - $\begin{array}{l}\text { Mean number of } \\
\text { disposable suction } \\
\text { catheters used/day } \\
\text { for each neonate }\end{array}$ & $8 \times 1=8 \mathrm{~L} . \mathrm{E}$ & $1 \times 1+1=2$ \\
- $\begin{array}{l}\text { Cost-effectiveness } \\
\text { (L.E) }\end{array}$ & 8 & 1 \\
\hline
\end{tabular}

\section{Discussion:}

The procedure of ETS is a common practice in the treatment of neonates who are admitted to the NICUs with respiratory problems. Most frequently, it is undertaken to remove excessive or retained secretions from a neonate's respiratory tract [4]. However, the modality of treatment has not been incorporated in most governmental health care settings in developing countries owing to the high cost, and scanty resources [21]. Therefore, train the nurses about applying disinfection technique for safe reuse of disposable suction catheters for neonates on mechanical ventilation, and evaluate whether the repetitive use of disinfected catheters is cost-effective over the single use may be investigated.

The findings of the present study revealed that nearly two thirds of the studied neonates were infected with Pseudomonas, Klebsiella, E-Coli and Staphylococcus. However, previous studies reported high levels of contamination in suction catheters that are in use. This contamination usually arises from the endotracheal tube and the patient's lower respiratory tract. Accordingly, the patient usually contaminates the catheter, rather than vice versa ${ }^{22}$ \& 23]. Therefore, re-infection might occur with the use of contaminated catheter(s), that is why the suction catheter either to be changed or to be disinfected.

The manufacturers of disposable suction catheters recommended that these tubes have been changed at regular intervals in an attempt to decrease the VAP rate $\left.{ }^{[24} \& 25\right]$. The development from reusable medical equipment and devices to disposable ones has brought convenience and ensuring safety with the apparently increased costs. 
Any hospital management team has to go through the consideration, when its health institute has to accept the use of disposable elements because of increasing labor cost, as well as availability and decreasing prices of commercial medical supplies over time [9]. For this reason, the cost of using a new suction catheter for intubated neonates each suction session and the cost of substances that used in its disinfection have to be calculated.

One study reported that, the suction catheter might be considered as an extension of the ventilator circuit, which does not need to be changed at regular intervals for infection control purposes. This might suggest that, suction catheters also does not need to be changed at regular intervals for cost saving but the maximum duration so that the disposable suction catheters can be reused safely is unknown ${ }^{[26]}$. In the present study it was found that, the average number of used catheter/day for each neonate was eight catheters, which cost eight Egyptian Pounds compared with about two Egyptian Pounds for disinfecting the catheter throughout the day. Therefore, it will save more than six Egyptian Pounds for each neonate/day. This coupled with the highly effectiveness of disinfecting technique that completely eradicated the isolated microbial clusters.

The current study technique included a step about cleaning the disposable catheter by flushing with $10 \%$ neutral detergent liquid solution. This is similar to a previous study by Hutchinson, and LeBlanc concerned with medical instrument cleaning. The investigators reported that, a neutral or near-neutral $\mathrm{pH}$ detergent solution commonly is used for medical instrument cleaning, because such solutions generally provide the best material compatibility profile and good soil removal (e.g., blood, mucous, and pus). However, cleaning solutions are not disinfectants, and can be inactivated by germicides [27], therefore, disinfectant solutions (acetic acid, and ethyl alcohol) were used in the present study to achieve the required outcomes or the safe reuse of disposable suction catheters.

The results of the present study also revealed that, by the effect of acetic acid 5\% and ethyl alcohol $95 \%$, all of the catheters become free from bacterial growth. In accordance with our findings, three researchers conducted a study about "surface analysis of clinically used endoscopic tubing", mentioned that acetic acid is a high-level disinfectant or sterilant for heat sensitive equipment. It enhances removal of organic material and characterized by rapid action against all microorganisms. They added that, special disadvantages of acetic acid is leaving residue ${ }^{[28]}$, so that in the current study, the catheters were rinsed inside and outside by water to overcome this problem. Moreover, Smith, tested the effect of ethyl alcohol against Mycobacterium tuberculosis in his study and reported that $95 \%$ ethanol killed the tubercle bacilli in sputum or water suspension within 15 seconds ${ }^{\text {[29]. }}$

Determining the effectiveness of the study technique, the tips of used suction catheters were sent in sterile containers to the microbiology laboratory to be cultured for bacterial growth. On the same context, Dancer, who conducted a study proposal about microbiological standards for surface hygiene in hospitals, declared that, although the effectiveness of high-level disinfection mandates effective cleaning, no real tests exist that it can be employed in a clinical setting to verify cleaning. The only way to ensure adequate surface cleaning is to conduct a reprocessing verification test (e.g., microbiologic sampling) ${ }^{[30] .}$

Prevention of infection is an important aspect for nurses in their clinical practice and guideline users are directed to identify the infection control elements of this clinical practice. This includes but is not limited to provide safe suctioning procedure that should be started, and completed using an aseptic technique to minimize the potential for the introduction of exogenous organisms 
into the respiratory tract of the critically ill patient ${ }^{[31] .}$

\section{Conclusion:}

Applying a disinfectant technique on disposable endotracheal suction catheters ensures its safe reuse without infecting the neonates on mechanical ventilation, as well as reducing the NICU' $s$ financial burden and at the same time minimize the NICU's waste disposals through repeated use of endotracheal suction catheters for admitted neonates who are in need for frequent suctioning.

\section{Recommendation:}

Based on the results, the present study recommended that:

-Applying disinfection technique on disposable suction catheters ensures its safe reuse for neonates on mechanical ventilation.

- Safe reuse of disposable suction catheters is highly recommended over the single use to reduce the cost-effectiveness of neonates on mechanical ventilation.

- Further studies should be conducted to find out for how long could the nurse reuse the disposable suction catheter after disinfection, and the effect of the study technique on the other types of microorganisms.

\section{Acknowledgments:}

I would like to thank all neonates as well as nurses and the head of the NICU, ElMansoura University Children's Hospital, as it would not have been possible to complete this work without their valuable contribution, co-operation and support.

\section{References:}

1. Shah, A., Kurth, C., Gwiazdowski, S., Chance, B., \& DelivoriaPapadopoulos, M. (1992). Fluctuation in cerebral oxygenation and blood volume during endotracheal suctioning in premature infants. $J$ Pediatr, 5, (120): 769-774.
2. Chang, V. (1995). Protocol for prevention of complications of endotracheal intubation. Crit. Care Nurse, 15, 19-26.

3. Kjonegaard, R., \& Fields, W. Current practice in airway management: A descriptive evaluation. American Journal Critical Care. 2010 Mar; 19(2):168-73

4. Jansson, M., Ala-Kokko, T., Yipalosaari, P., \& Kyngas, H. (2013). Evaluation of endotracheal-suctioning practices of critical-care nurses - An observational correlation. Journal of Nursing Education and Practice, 7, (3): 99-105.

5. Yu, H., M., Chen, L., H., \& Yuan, T., M. (2007). Risk factors and outcomes for ventilator-associated pneumonia in neonatal intensive care unit patients. $J$ perinat Med., 35, (4): 334-8.

6. Gilmour, D. (2000). Is aseptic technique always necessary? Journal of Community Nursing, 14, 4.

7. Wilson, J. (2001). Infection Control in Clinical Practice. (2nd ed.). London: Bailliere Tindall, ISBN 0702025542.

8. American Thoracic Society Board of Directors. (2000). Care of the Child with a Chronic Tracheostomy: suctioning clean vs. sterile consensus. American Journal of Respiratory and Critical Care Medicine, 161: 297-308.

9. Shabino, C., L., Erlandson, A., L., \& Kopta, L., A. (1986). Home cleaningdisinfection procedure for tracheal suction catheters. Pediatr Infect Dis., 5, (1): 54-8.

10. Nanta, P., Senarat, W., \& Tribuddharat, C. (2005). CostEffectiveness and Safety of Reusable Tracheal Suction Tubes. J Med Assoc Thai., 88, (10): 86-8.

11. Stone, P., W., Larson, E., \& Kawar, L., N. (2002). A systematic audit of economic evidence linking nosocomial 
infections and infection control interventions: 1990-2000. Am J Infect Control, 30, (3): 145-52.

12. Nguyen, Q., V. (2006). Hospital acquired infections. E-medicine. [Online] Available: http://www .emedicine.com/PED/topic1619.htm.

13. Safdar, N., Dezfulian, C., \& Collard, H., R. (2005). Clinical and economic consequences of ventilator-associated pneumonia: a systematic review. Crit Care Med., 33, 2184-93.

14. Centers for Disease Control and Prevention. (2004). Guidelines for preventing health-care associated pneumonia, 2003: recommendations of $\mathrm{CDC}$ and the Healthcare Infection Control Practices Advisory Committee. MMWR., 53, 1-35.

15. Foglia, E., Meier, M., D., \& Elward, A. (2007). Ventilator-Associated Pneumonia in Neonatal and pediatric Intensive Care Unit Patients. Clin Microbiol Rev., 20, (3): 409-425.

16. Zack, J., E., Garrison, T., \& Trovillion, E. (2002). Effect of an education program aimed at reducing the occurrence of ventilator-associated pneumonia. Crit Care Med., 30, 240712.

17. Rutala, W., A., \& Weber, D., J. (2008). The Healthcare Infection Control Practices Advisory Committee (HICPAC). CDC Guideline for disinfection and sterilization in healthcare facilities, 1-185.

18. Alp, E., \& Voss, A. (2006). Ventilator associated pneumonia and infection control. Annals of Clinical Microbiology and Antimicrobials, 5, 7.

19. Rutala, W., A., \& Weber, D., J. (1999). Disinfection of endoscopes: review of new chemical sterilants used for high-level disinfection. Infect. Control Hosp. Epidemiol, 20, 69-76.
20. Ali, Y., Dolan, M., J., Fendler, E., J., \& Larson, E., L. Alcohols. (2001). In: Block S.S., (ed.). Disinfection, sterilization, and preservation. Philadelphia: Lippincott Williams \& Wilkins, 229-54.

21. Bhutta, Z., A., Darmstadt, G., L., Hasan, B., S., \& Haws, R., A. (2005). Community-Based Interventions for Improving Perinatal and Neonatal Health outcomes in Developing Countries: A Review of the Evidence. Pediatrics, 115, (2): 519-617.

22. Ritz, R., Scott, L., R., Coyle, M., B., \& Pierson, D., J. (1986). Contamination of a multiple- use suction catheter in a closed-circuit system compared to contamination of a disposable, singleuse suction catheter. Respir Care, 31, (11): 1086-1091.

23. Freytag, C., C., Thies, F., L., Konig, W., \& Welte, T. (2003). Prolonged application of closed in-line suction catheters increases microbial colonization of the lower respiratory tract and bacterial growth on catheter surface. Infection, 31, (1): 31-37.

24. Zack, J., E., Garrison, T., Trovillion, E., Clinkscale, D., Coopersmith, C., M., Fraser, V., J., \& Kollef, M., H. (2002). Effect of an education program aimed at reducing the occurrence of ventilator-associated pneumonia. Crit Care Med., 30, (11): 2407-2412.

25. Hess, D., Kallstrom, T., Mottram, C., Myers, T., Sorenson, H., \& Vines, D. (2003). Care of the ventilator circuit and its relation to ventilator-associated pneumonia: Evidence-Based Clinical Practice Guidelines. Respiratory Care, 48, (9): 869-879.

26. Stoller, J., K., Orens, D., K., Fatica, C., Elliott, M., Kester, L., and Woods, J. (2003). Weekly versus daily changes of in-line suction catheters: impact on rates of ventilator-associated pneumonia and associated costs. Respir Care, 48, (5): 494-499. 
27. Hutchisson, B., \& LeBlanc, C. (2005). The truth and consequences of enzymatic detergents. Gastroenterol. Nurs, 28, 372-6.

28. Tucker, R., C., Lestini, B., J., \& Marchant, R., E. (2008). Surface analysis of clinically used expanded PTFE endoscopic tubing treated by the STERIS PROCESS. In: Rutala, W.A., Weber, D.J., \& the Healthcare Infection Control Practices Advisory Committee (HICPAC) (eds.). CDC Guideline for disinfection and sterilization in healthcare facilities.

29. Smith, C., R. (2008). Alcohol as a disinfectant against the tubercle bacillus.
In: Rutala, W.A., Weber, D.J., and the Healthcare Infection Control Practices Advisory Committee (HICPAC) [eds.]. CDC Guideline for disinfection and sterilization in healthcare facilities.

30. Dancer, S., J. (2004). How do we assess hospital cleaning? A proposal for microbiological standards for surface hygiene in hospitals. J. Hosp. Infect., 56, 10-15.

31. Rolls, K., D, \& Elliott, D. (2008). Using consensus methods to develop clinical practice guidelines for intensive care: the intensive care collaborative project. Aust Crit Care., 21, (4): 200-15 